\title{
Improving learning computer architecture through an educational mobile game
}

\author{
Ahmed Tlili, Fathi Essalmi and Mohamed Jemni
}

\author{
* Correspondence: \\ ahmed.tlili23@yahoo.com \\ Research laboratory of Technologies \\ of Information and Communication \\ \& Electrical Engineering (LaTICE), \\ Tunis higher school of engineering \\ (ENSIT), University of TUNIS, 5, \\ Avenue Taha Hussein, B.P. 56, 1008 \\ Tunis, Tunisia
}

\begin{abstract}
Many studies have reported the efficiency of using educational games to teach a particular subject. With the rapid growth of mobile technology, mobile devices have become very popular and have reached a very high spread. This allowed educational mobile games to gain an increasing attention from researchers and practitioners in the learning field. At the same time, many learners find learning the computer architecture subject dry and hard using the traditional way in classrooms. This paper presents an educational mobile game to provide an interactive, motivating and a mobile learning experience of the computer architecture subject. Twenty seven undergraduate learners participated in evaluating the game using three instruments, namely technology acceptance model questionnaire, 5 stars rating method and interviews. The obtained experimental results showed that these learners were very satisfied and motivated to learn computer architecture using this designed educational game. Besides, they reported that they are willing to use it again in the future.
\end{abstract}

Keywords: Educational games, Platform genre, Computer science education, Mobile learning, Mobile devices

\section{Introduction}

During the last few years, one of the problems that teachers have been struggling with is learners' boredom in class (Daschmann et al., 2011). This can be due to the meaningless or repetitive learning tasks (Reid, 1986), overly abstract activities (Condry, 1978) and tasks being less or too challenging (Cullingford, 2002; Moneta and Csikszentmihalyi, 1996). Consequently, learners become frustrated, cut classes (Fallis and Opotow 2003) and even drop out of school (Dow, 2007). In particular, many learners find learning the computer architecture subject using the classical method in classrooms difficult and not motivating. This is because of the many computer components that learners have to go through, understand and memorize (Processor, memory, hard disk, etc.) (Tlili et al., 2015). It is scientifically proven that learners often do less than what teachers expect when it comes to learning computer architecture courses (Porter et al., 2013). Moreover, according to a study mentioned in (Waraich, 2004), learners who have learnt computer architecture and to be precise "Computer Systems Organization" chapter using the traditional way have encountered many problems. For example, the learning content was "dry" and "not very interesting". Therefore, new methods for teaching computer architecture are required.

(C) 2016 Tlili et al. Open Access This article is distributed under the terms of the Creative Commons Attribution 4.0 International License (http://creativecommons.org/licenses/by/4.0/), which permits unrestricted use, distribution, and reproduction in any medium, provided you give appropriate credit to the original author(s) and the source, provide a link to the Creative Commons license, and indicate if changes were made. 
With the advances of Technology Enhanced Learning (TEL), new opportunities in education to improve teaching methods and learning quality have improved. Thus, learning mediums and environments have also evolved over time. This evolution can be seen from the classic learning with blackboard in classrooms environment to the online, open or mobile learning environments. In this context, this paper focuses on using mobile technology to present a newly designed educational mobile game to provide an interactive, motivating and a mobile learning experience of the computer architecture subject. The popularity, affordability and rapid spread of mobile devices have created new ways of learning (Shuler et al. 2013). According to Kambourakis et al. (2004), mobile learning or m-learning is the combination of two fields which are electronic learning and mobile computing. Attewell and Savill-Smith (2005) defined mobile learning as the use of wireless technological devices which can be carried in the learner's pocket for learning.

This paper is structured as follows: Related work presents related work regarding educational games and mobile learning. Game implementation presents the game implementation. In particular, it presents the followed game design strategies and the implemented game learning activities. Experiment lists the used research instruments and the experimental results after using the game. Conclusion, limits and potential future directions concludes the paper with a summary of the findings, the limits and potential research directions.

\section{Related work}

This section presents the motivation behind using educational games in particular among other learning tools. Besides, it defines mobile learning and lists examples of educational mobile games reported in the literature.

\section{Educational games}

Prensky (2005) claimed that the motivating factors used before are not effective with the present generation of learners. Beck and Wade (2004) talked about a new type of generation called gamer generation. Thus, it is claimed that this generation evolution has affected the learner's skills (visual and spatial), preferences and the way they think (Oblinger et al. 2005). Digital games are considered as the fastest growing industry in America. Based on a new report made by the Entertainment Software Association (2014), video game industry's revenue in the United States grew by $9 \%$. This has touched communities across the country, contributing $\$ 6.2$ billion to the American economy in 2012. Prensky (2003) mentioned that the children's attitudes towards their games are completely different from the ones towards school. Thus, it is not surprising that there is a large and growing interest in using games in education.

In educational games, learners are playing within a game scenario while trying to complete a series of learning tasks by themselves (single player games) or in groups (multiplayer games) (Nelson et al., 2011; Paraskeva et al., 2010). Prensky (2001) stated that these games made learning more fun and engaging. Carbonaro et al. (2006) found that educational games add the immersion criterion which does not exist in classrooms. Not only that, but these games support as well, providing an adaptive learning experience by modeling learners (Khenissi et al., 2015, Tlili et al., 2016). 
A good and effective educational game should combine good learning content and game design (Oblinger, 2006; Amory and Seagram, 2003). Prensky (2001) recommended that a good educational game design should combine a balanced amount of both fun and educational value. Koster (2004) stated that game design is not an easy task since it is not a precise science. Also, not understanding the learning process within games can affect implementing a structured instructional game design (Egenfeldt-Nielsen, 2005). Furthermore, Plass et al. (2011) listed three elements that should be present while designing an educational game, namely game element which describes the game play activity, learning element which describes the activities that are known with their learning objective and assessment element which describes high level activities that aim to assess learners.

\section{Mobile learning}

With the rapid growth of mobile technologies, different mobile devices (e.g. mobile phones, tablets) have appeared and have become indispensable in people's life no matter where they are. In fact, 129.4 million people in the U.S. (almost half the U.S. population) own smartphones (comScore Reports January 2013 U.S. Smartphone Subscriber Market Share, 2013). These devices compared to computers are smaller, wireless, simple and cheaper (Fotouhi-Ghazvini et al., 2009). This helped them to be used in different domains, including education where the learning is mobile. In this type of learning, the learner is not limited to a predetermined place or location (O'Malley et al. 2005). Besides, According to Hashemi et al. (2011), mobile learning can be defined as the use of mobile devices and technologies to facilitate, support, enhance and extend the reach of teaching and learning. Mobile technologies and Internet made mobile learning gain more attention by researchers (Kinshuk et al., 2013).

As a result, new learning strategies are created such as "Just-In-Time" learning strategy where learners instantly access information and learn when it is needed without too much effort. For example, when they are waiting in a queue or for their public transportations, they can make use of that time and use their mobile devices to learn (Lavin-Mera et al., 2009). Also, mobile devices made "situated" learning strategy possible. In this strategy, learners can play and learn in an environment context similar to the subject content. For example, in (Chen et al., 2014), learners use their mobile devices to learn the culture of Taiwan (e.g. religion) by being in a temple and a church. Jacobs (2013) stated that "always on, always connected mobile devices in the hands of students can improve educational outcomes".

Unsurprisingly, the mobile game industry has grown by $32 \%$ annually, which led in 2012 to an increase of $16 \%$ in its revenue generating over $\$ 9$ billion in U.S. (Nouch 2013). In particular, various mobile games are used for educational purposes with different pedagogical objectives. For example, Hssina et al. (2014) presented a game which aims to teach kids about different learning activities such as letters, words and mathematical calculations. In this game, the learners read the story of the game, then, they move to answer correctly the questions presented by the game. After the playing process, the game results and high score is displayed. Ketamo (2002) developed an adaptive geometry game where learners use a stylus to mark the polygon from a list of given forms in order to win. Sandberg et al. (2011) developed a game which aims to 
teach English as a second language for primary school children. The English lesson is about zoo animals and their characteristics. This game is played in a zoo. Thus, children can see these animals in reality. Then, they can answer different quizzes about them presented by the game. Huizenga et al. (2007) developed a game which aims to teach learners about the history of Amsterdam. The learners are divided into two teams. Each team has a member equipped with GPS walking through the streets of Amsterdam. This allows both teams to track the position of their team member and guide him/her to finish different assignments. Furió et al. (2013) developed a game which aims to transmit the knowledge about multiculturalism, solidarity and tolerance to learners. This is done by teaching them about the poorest continents in the world (Africa, Asia and Central and South America). The learners will have to follow the guide character and collect objects from these continents such as food. Then, they have to distribute it among poor people. Aslan (2011) developed a mobile game to teach middle school learners fraction in mathematic. In this game, the learner uses the factory's warehouse candy to fulfill the customer order by partitioning this candy and then iterating through appropriate number of times based on the given request. Table 1 summarizes the educational games presented above. In particular, the second column presents the pedagogical objectives of these games. Column three presents the operating system used for each game.

As shown in Table 1, various educational mobile games are found dedicated to different operating systems (Android, iOS) with different pedagogical objectives (English, math, history, etc.) and for different ages (primary or high school learners). However, among the reported games in the literature, none of them currently supports learning the computer architecture subject in a fun and motivating way. Therefore, to overcome this problem, a newly designed educational mobile game is presented.

\section{Game implementation}

To deliver a motivating learning of the computer architecture subject, a mobile platform game for Android devices was developed. This game is called Science Soldier. This section details the different strategies followed while designing the game. Also, it presents the different learning activities and functionalities used within the game to deliver the learning content.

Table 1 Examples of educational mobile games

\begin{tabular}{lll}
\hline Game & Pedagogical objective & Operating system \\
\hline Edugame (Hssina et al., 2014) & $\begin{array}{l}\text { Teaches construction of words, recognition of } \\
\text { letters or mathematical operations }\end{array}$ & Android \\
Geometry game (Ketamo, 2002) & Teaches geometry & iOS. \\
MEL game (Sandberg et al., 2011) & Teaches English as a second language & Android \\
Frequency 1550 (Huizenga et al., 2007) & Teaches the history of Amsterdam & iOS \\
Candy Factory (Aslan 2011) & Teaches fraction in mathematic & iOS \\
(Furió et al. 2013) & $\begin{array}{l}\text { Teaches the knowledge about multiculturalism, } \\
\text { solidarity and tolerance }\end{array}$ & iOS. \\
\hline
\end{tabular}




\section{Game design}

Science Soldier is a platform game genre. This genre is based on the movement through a series of levels, by way of running, climbing, jumping, and other means of locomotion (Wolf, 2004). The reason of choosing this genre in particular is because it is very known by both male and female learners. This is seen since most of them played a platform game before (e.g. Super Mario game). Besides, this genre is characterized with its simple and easy game play. Thus, learners will play the game and learn without any additional efforts. This keeps them motivated during the learning process. In addition, platform games usually present their playable worlds in an incremental level of difficulty. This satisfies the important characteristic that should be defined within educational games, namely challenge (Malone and Lepper, 1987). In the game, the learners have to control their game character (move forward, backward and jump) and lead him to kill the devil man in order to save the city and win.

Mobile devices differ from computers in their size in general and their screen size in particular. Besides, these devices differ from computers in the way to control the game. Usually, computers use the keyboard and mouse as inputs while mobile devices use touch screen technology. Lavín-Mera et al. (2008) insisted that the design experience for mobile devices is not the same for computers. This is because the content displayed easily on computers may not fit mobile devices' screen. Therefore, the following design strategies were taken into consideration while designing the game:

- The amount of displayed information: It was taken into consideration to make it more readable and visible on the screen. This can affect positively the comprehension and the memorization of the presented information regarding computer architecture. Churchill (2011) recommended that the displayed information on the mobile device's screen should be short.

- The game graphics: It was resized with keeping into consideration the graphic clarity. High quality graphics increase the likeability of a game. This can increase the immersion experience while learning using the game.

- Virtual buttons: To control the game character, virtual buttons on the touch screen were designed. However, this technology can be tricky, especially for learners who have fat fingers (Siek et al., 2005). Therefore, these buttons were designed with a large size. This facilitates controlling the game by all types of learners.

\section{Game learning activities}

Different learning activities were implemented within the game to deliver the learning content. These activities are as follows:

- Collecting information: Within the game, the learner can use his/her game character to collect different item (coins, key, etc.). Each one of these items gives the learner information regarding the computer architecture subject.

- Jumping through answers: In this learning activity, the learner has to control the game character and jump from a rock to another. Each rock has an answer to a question. If the learner jumps on the wrong rock, it falls down and he/she loses. 
- Shooting answers: The learner has to control his/her game character in its zeppelin and fight a flying enemy. In this learning activity, this enemy will give the learner a question and he/she has to shoot the correct answer. If the answer is correct the enemy's blood level decreases. Otherwise, the learner's blood level decreases.

Figure 1 presents a screenshot from one of the learning activities defined above (shooting answers). The learner has to control the game character in its zeppelin (using virtual buttons) and shoot the correct answer (displayed on the two missiles) of a given question (written in the box) by the monster. Every time an answer is shot (correct or wrong), a feedback regarding that question is displayed.

In addition to these learning activities, after finishing each level, the game presents an exercise which aims to refresh the mind of the learners about the learnt information. This exercise is a question with multiple choices. The learners can submit their answers by touching the correct one. An immediate feedback will be displayed based on the learner's choice.

Furthermore, to support the delivered learning content and to make learners motivated while learning, the game uses the following supportive functionalities:

- A rewarding system: For every correct answer or step the learner does, a clapping sound will be played. This makes the learners feel that they did well and increases their confidence and motivation level (McClarty et al., 2012).

- A feedback system: The game provides guidance and further details during the learning process. This helps learners to enhance their level of knowledge regarding the computer architecture subject. According to Oblinger (2004), feedback supports learners in making progress within the interactive process of probing, reacting, hypothesizing and planning.

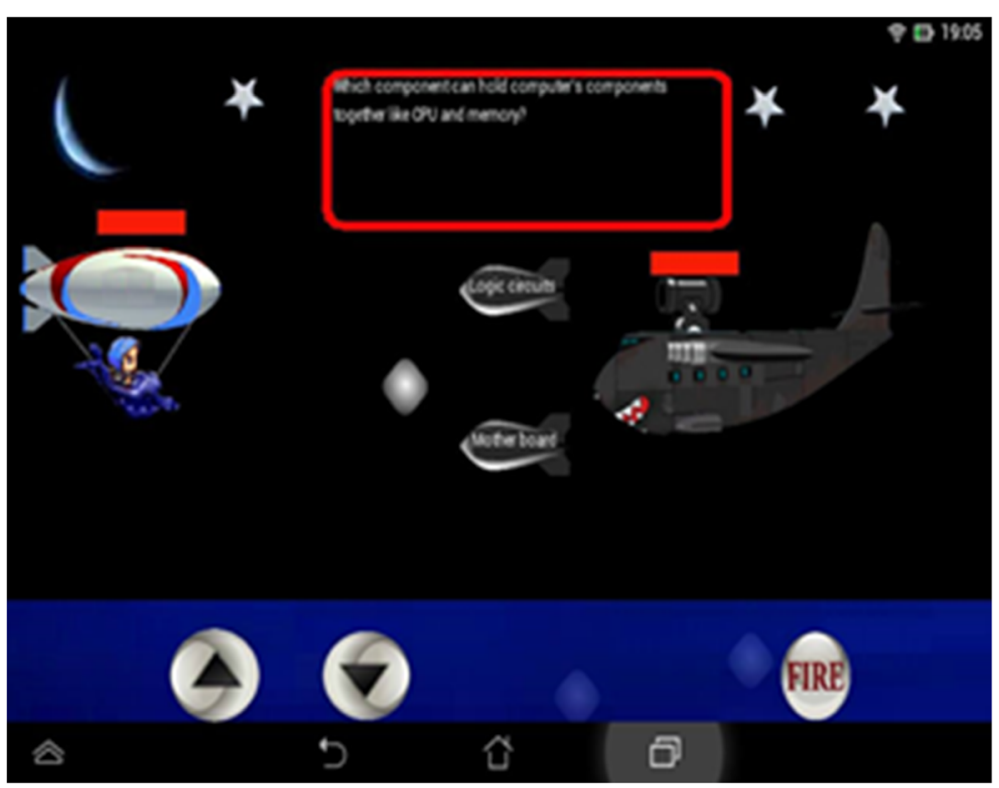

Fig. 1 Screenshot of the shooting answers learning activity 
- An incremental level of difficulty: The game provides ample opportunities for "challenge", which is an important characteristic of educational games, by using goals and incremental levels of difficulty (Malone and Lepper, 1987).

\section{Experiment}

This section presents the hypothesis of this research. Besides, it introduces the participants of the conducted experiment and the used research instruments to validate the game. Furthermore, this section presents the obtained experimental results.

\section{Hypothesis}

Learners find the traditional method of learning the computer architecture subject in classrooms hard and not motivating. Therefore, this study uses the features of educational games and mobile technology to promote a motivating, easy and fun learning experience of the computer architecture subject. Currently, there is no educational game is designed for this purpose. This is hypothesized as follows:

Educational mobile games can enhance the learners' learning experience of the computer architecture subject.

\section{Participants}

Twenty seven undergraduate learners ( 9 females and 18 males) aged between 19 and 22 and all of them are with a fair amount of English skills, participated voluntarily in evaluating the designed game. These learners are all majoring in computer science, hence, they have good skills towards using computers and mobile devices. Besides, they have all reported that they frequently play games on their mobile phones. The learners were chosen with the same background and to fit well with the aim and context of this experiment, to avoid the implication of the learners' background differences on the obtained results. The instructor starts by telling them the goal of the experiment. Then, he moves to present short instructions on how to play the game. After the learningplaying process, the learners' satisfaction and likeability of the game were evaluated. Besides, their opinions regarding the game were collected. Figure 2 shows examples of the learners playing the game on their tablets. In particular, Fig. 2a shows a learner is

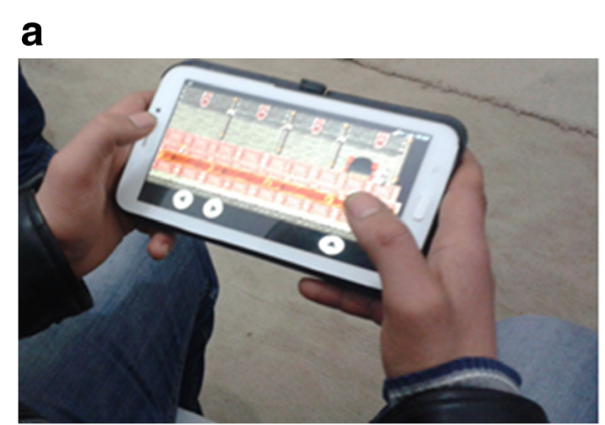

\section{b}

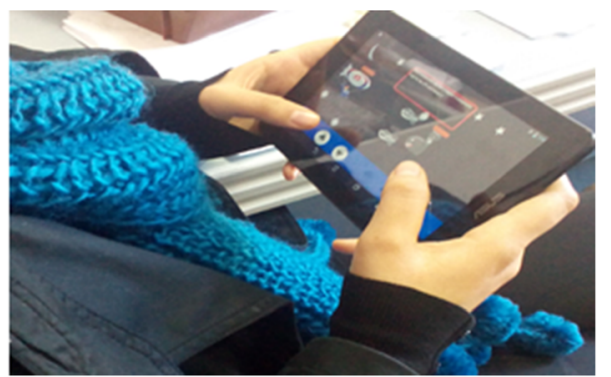

Fig. 2 a An example of a learner playing the game at home. b An example of a learner playing the game at class 
playing the game while he is at home (informal learning), while Fig. 2b shows a learner is playing the game while she is at class (formal learning).

\section{Instruments}

To evaluate Science Soldier, three instruments were used which are as follows:

Technology Acceptance Model (TAM) questionnaire: It is a Likert scale questionnaire which aims to evaluate the learner's satisfaction after using the game. After the learning-playing process, the learners have to answer by giving points which range from 1: Strongly agree to 7: Strongly disagree. TAM is a widely used model in information science (King and He, 2006). Besides, it has been used to validate different application such as electronic courseware (Park et al., 2007) and multimedia learning environment (Saadé et al., 2007). The questionnaire contains 13 statements and covers the four variables of TAM which are (Davis, 1989): (1) Ease of use (EOU) which defines the degree to which learners find the game easy to use and free of effort, (2) Usefulness (U) which defines the degree to which learners think that the game will enhance their level of knowledge while learning computer architecture, (3) Attitude towards using the game (ATT) which defines the degree to which learners report a favorable and positive attitude towards the game after using it and, (4) Intention to use the system (INT) which defines the degree to which learners are willing to use the game again in the future to learn computer architecture.

5 stars rating method: To evaluate the learners' likeability of the new educational game after using it, a very popular method which is the 5 stars rating method is used. This method is frequently used by different online stores such as Amazon, Netflix, and iTunes (Teamhively, 2011). The learners have to show the level of their likeability of the game by selecting the number of stars that represent it (number of stars ranges from 1: low likeability level to 5: high likeability level).

Interviews: To investigate the opinion of the learners towards the game, live interviews were used. This method allows learners to be more forthcoming in their answers (Bryman and Burgess, 1998). After the learning-playing process, learners were asked about their opinions and how they felt while learning-playing using the game; were they motivated, satisfied, or bored? Did they find the game interesting or not? This helps evaluating Science Soldier through their given feedback.

\section{Results}

This section lists and discusses the obtained experimental results of the three instruments (TAM questionnaire, 5 stars rating method and interviews) used to validate the game. These results are as follows:

\section{Learners' satisfaction}

Satisfaction is the learner's perceived value of their educational experiences in an educational environment. It is an important dimension that should be considered in the evaluation of a given course or a learning system (Garrison and Kanuka, 2004). Therefore, to evaluate the learners' satisfaction while using the game, learners were 
requested to answer a TAM questionnaire, which is presented in Table 2, after the learning-playing process using the game.

Prior to conducting further analyzes, it is important to evaluate the reliability of this questionnaire's measurement. Thus, the Cronbach's alpha for each variable (presented in the TAM questionnaire) was calculated. Table 3 presents the results of this evaluation. Also, it presents the number of items defined in each construct of the questionnaire.

If Cronbach's alpha is equal or greater than 0.7, it shows that the instrument is reliable (Yu, 2001). As shown in Table 3, the questionnaire's measurements are reliable since all the values of the four variables are greater than 0.7 .

Furthermore, medians and averages of the learners' answers to the questionnaire are calculated. In general, an average and median near 1 indicate that learners are satisfied with the designed game. However, an average and median near 7 indicate that learners are dissatisfied with the designed game. Table 4 lists the values of medians and averages for the variables EOU, U, ATT and INT.

As shown in Table 4, all values of the average and median are completely far from 7 (between 1 and 2), thus, the learners were very satisfied with this designed educational game. Satisfaction is highly linked to motivation (Myers, 2012). Besides, this can promote a higher level of engagement and learning performance (Sahin and Shelley, 2008; Wickersham and McGee, 2008). In particular, and despite the high satisfaction rate obtained with this designed game, some learners had lower intention of using the game in the future. This could be because some learners, and depending on their personalities, prefer other game genres and not "platform" genre specifically (Peever et al., 2012). Consequently, they decided to not return to the game again.

In addition, the relationship between the variables of the TAM questionnaire were investigated by analyzing the correlation (Pearson's $r$ value) between the EOU (ease of use) variable and the rest of the variables (U, ATT, INT). As shown in Table 5, there is a significant positive relationship between the EOU and all the other three variables (U, ATT, INT).

Table 2 TAM questionnaire

\begin{tabular}{ll}
\hline Variables & Statements \\
\hline U & Using this game enhances the learning process \\
& Using this game improves the learning effectiveness \\
& Overall, I find this game useful for learning a new course \\
& Learning using this game is easy for me \\
& I find it takes a lot of effort to learn using this game \\
& Overall, I find this game easy to use \\
& I dislike the idea of using this game \\
ATT I have a generally favorable attitude toward using this game & I believe it would be a good idea to use this game for learning \\
& Using this game is a foolish idea \\
& I intend to use this game during my learning process \\
INT & I will return to this game often \\
& I intent to use this game frequently for learning \\
\hline
\end{tabular}


Table 3 Cronbach's alpha values

\begin{tabular}{llc}
\hline Variable & Number of items & Cronbach's alpha \\
\hline EOU & 3 & 0.723 \\
U & 3 & 0.758 \\
ATT & 4 & 0.721 \\
INT & 3 & 0.737 \\
\hline
\end{tabular}

Learners' likeability

One of the principal assets of games when compared to other educational programs is likeability and the resulting motivation for students (Furió et al., 2013). Many studies focused on the likeability of games, which are not necessarily educational (Fabricatore et al., 2002). Virvou and Katsionis (2008) stated that it is very important to evaluate the likeability of a game because if the learners find it not likeable, then, there is no point of using it as an educational tool. Figure 3 illustrates the results of the 5 stars rating method that was done by the learners. The axis of abscissa represents the number of given stars. While the axis of ordinates shows the number of votes given to each star (represented in the axis of abscissa).

As shown in Fig. 3, twelve learners (out of 27) rated the game 4 stars, while, six learners rated the game 3 stars and six learners rated the game 5 stars. However, only two learner rated the game 1 star. The obtained results reflect the learners' high level of likeability of the game. Also, this confirms their high level of satisfaction towards the designed game (presented in Table 3) which affects positively their likeability of the game. The ease of use of the game has affected positively the degree of its likeability (Virvou and Katsionis, 2008).

\section{Learners' opinions}

To have straight opinions from the learners about their learning experience using Science Soldier; which part of the game did or did not like? Are there any further recommendations to enhance the game? Their opinions were collected via short and unstructured interviews. In these interviews, learners talked freely about their opinions regarding the game design, elements and functionalities. These opinions were saved and filtered by removing the ones which did not help in evaluating Science Soldier. Furthermore, similar opinions were grouped together. Table 6 lists some of the grouped learners' opinions collected during the interview.

As shown in Table 6, the learners were really interested in learning the computer architecture subject using Science Soldier. Besides, some of them are willing to use it more often in learning, while, others wished that this educational game can deliver other learning courses so they can use it with other subjects. These findings provide evidence that learners were highly motivated to learn using the game. Furthermore, a new set of suggestions and recommendations were given by learners in order to make

Table 4 Medians and averages values

\begin{tabular}{lllll}
\hline Construct & EOU & $U$ & ATT & INT \\
\hline Average & 2.01 & 1.22 & 1.67 & 2.41 \\
Median & 2 & 1 & 1 & 2.17 \\
\hline
\end{tabular}


Table 5 Correlation results

\begin{tabular}{lllll}
\hline Factors & & $U$ & ATT & INT \\
\hline EOU & Pearson's r value & $.566^{\mathrm{a}}$ & $485^{\mathrm{a}}$ & $691^{\mathrm{a}}$ \\
& $p$-value & .000 & .000 & .000 \\
& $N$ & 27 & 27 & 27 \\
\hline
\end{tabular}

${ }^{a}$ Correlation is significant at 0.01 level

the game more fun and playable, such as making the game levels longer. To conclude, the learners' opinions were very motivating to further enhance the game and use it in teaching the computer architecture subject.

\section{Conclusion, limits and potential future directions}

This paper presented an educational mobile game called Science Soldier. It is developed for Android platforms and it aims to make the learning experience of the computer architecture subject fun, motivating and interactive compared to the classical method in classrooms. With the use of mobile technology, Science Soldier allowed learners to learn computer architecture anywhere and anytime through their mobile devices (formal and informal learning). To evaluate the efficiency of this game, twenty seven learners played this game. The obtained results showed that they were very satisfied with this designed educational game. This has affected positively their likeability level of the game. Also, it showed that this game made learning the computer architecture subject interesting and fun. Furthermore, learners suggested further recommendations to enhance the game in the future.

On the other hand, some limitations are found which may limit the generalizability of the results. For example, the learners with Apple mobile devices could not play the game. This affected the number of learners participating in the evaluation process of the game (only 27 learners). Besides, the proposed experiment did not cover other important dimensions, such as the impact of the game on the learners' level of knowledge and cognitive load.

Future work will focus on creating another version of Science Solider dedicated to iOS operating systems, then, further evaluate it with more learners and with other

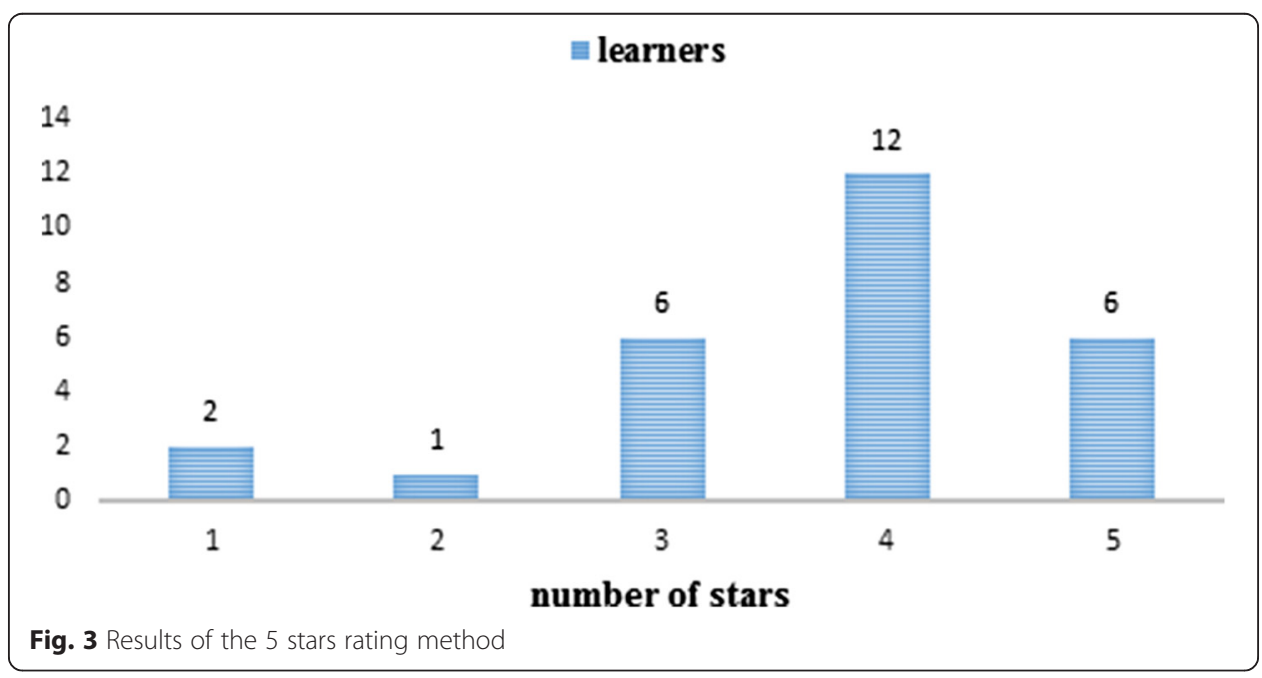


Table 6 Examples of the grouped learners' opinions

\begin{tabular}{ll}
\hline Learners & Opinions \\
\hline Learner1 & I really liked learning using this educational game. \\
Learner2 & I think that more additional work on the game design will even make it better. \\
Learner3 & I loved this game and I will use it more often in the future. \\
Learner4 & I recommend making the game levels longer. This will help us learn and play more. \\
Learner5 & I wish that the game can deliver other courses. This will make it more efficient. \\
\hline
\end{tabular}

dimensions (e.g. learner's cognitive load). To do so, it is possible to refer to cross platform applications. These applications use a single code to design and develop software, including games for all mobile devices (Litayem et al., 2015). This will reduce the overhead time and cost dedicated to prepare educational mobile games for each platform. Furthermore, an educational game generator for this game will be created. In this generator, the teacher will have an interface where he/she can enter new information about his/her course within the game and generate a new instance of it. This allows the reusability of the game with any given course without the need for any programming skills. Consequently, the learners will have the chance to learn other provided courses using the game.

\section{Endnote}

This work is an extension of the paper "[this information has been removed for the double-blind reviewing process]”. (Tlili et al., 2015).

Competing interests

The authors declare that they have no competing interests.

Authors' contributions

All authors read and approved the final manuscript.

Received: 10 February 2016 Accepted: 2 May 2016

Published online: 10 May 2016

References

A Amory, R Seagram, Educational game models: conceptualization and evaluation: the practice of higher education, In South African Journal of Higher Education, 17(2), (2003)

S Aslan, Game-based Improvement of Learning Fractions Using iOS Mobile Devices (Doctoral dissertation, Virginia Polytechnic Institute and State University), (2011)

J Attewell, C Savill-Smith, Mobile Learning Anytime Everywhere (Learning and Skills Development, Agency, London, 2005)

J Beck, M Wade, Got game: How the gamer generation is reshaping business forever (Harvard Business Press, Boston, 2004)

A Bryman, R G Burgess, Qualitative Research: Sage Publication. CA: Thousand Oaks, (1998)

M Carbonaro, M Cutumisu, H Duff, S Gillis, C Onuczko, J Schaeffer, A Schumacher, J Siegel, D Szafron, K Waughb, Adapting a commercial role-playing game for educational computer game production. Game on North America, 2006, pp. 54-61

CP Chen, JL Shih, YC Ma, Using instructional pervasive game for school children's cultural learning. J Educ Technol Soc 17(2), 169-182 (2014)

D Churchill, Conceptual model learning objects and design recommendations for small screens. J Educ Technol Soc 14(1), 203-216 (2011)

comScore Reports January 2013 U.S. Smartphone Subscriber Market Share, Retrieved December 20, 2015, from http://www.comscore.com/Insights/Press-Releases/2013/3/comScore-Reports-January-2013-U.S.-SmartphoneSubscriber-Market-Share (2013)

J Condry, The role of incentives in socialization, in The hidden costs of reward: new perspectives on the psychology of human motivation, ed. by M. Lepper, D. Greene (John Wiley \& Sons, New York, 1978), pp. 179-192

C Cullingford, The best years of their lives? Pupils' experience of school (Kogan Page, London, 2002)

EC Daschmann, T Goetz, RH Stupnisky, Testing the predictors of boredom at school: Development and validation of the precursors to boredom scales. Br. J. Educ. Psychol. 81(3), 421-440 (2011)

FD Davis, Perceived usefulness, perceived ease of use, and user acceptance of information technology, MIS quarterly, 1989, pp. 319-340

RR Dow, Passing time: An exploration of school engagement among Puerto/Rican Girls. Urban Rev. 39(3), 349-372 (2007) 
S Egenfeldt-Nielsen, Beyond edutainment: Exploring the educational potential of computer games. Unpublished PhD, IT-University of Copenhagen, Copenhagen, (2005)

Entertainment Software Association, retrieved from http://www.theesa.com/wp-content/uploads/2015/03/ESA-2014Annual-Report.pdf (2014)

C Fabricatore, M Nussbaum, R Rosas, Playability in action videogames: A qualitative design mode. Hum. Comput. Interact. 17(4), 311-368 (2002)

R Fallis, S Opotow, Are students failing school or are schools failing students? Class cutting in high school. J. Soc. Issues 59(1), 103-119 (2003)

F Fotouhi-Ghazvini, RA Earnshaw, D Robison, PS Excell, The MOBO City: A Mobile Game Package for Technical Language Learning, 2009, pp. 19-24

D Furió, S Gonzalez-Gancedo, M Juan, I Seguí, N Rando, Evaluation of learning outcomes using an educational iPhone game vs. traditional game. Comput. Educ. 64, 1-23 (2013)

DR Garrison, H Kanuka, Blended learning: Uncovering its transformative potential in higher education. Internet High. Educ. 7, 95-105 (2004)

M Hashemi, M Azizinezhad, V Najafi, AJ Nesari, What is mobile learning? Challenges and capabilities. Procedia-Soc. Behav. Sci. 30, 2477-2481 (2011)

B Hssina, M Erritali, B Bouikhalene, A Merbouha, Edugame an Android game for teaching children. Int. J. Innov. Appl. Stud. 9(4), 1531 (2014)

J Huizenga, W Admiraal, S Akkerman, G Ten Dam, Learning history by playing a mobile city game, in Proceedings of the 1st European conference on game-based learning, 2007, pp. 127-134

I Jacobs, Modernizing Education and Preparing Tomorrow's Workforce through Mobile Technology. Paper presented at thei4j Summit, 2, (2013)

G Kambourakis, DPN Kontoni, I Sapounas, Introducing attribute certificates to secure distributed E-learning or M-learning services, in Proceedings of the IASTED International Conference, 2004, pp. 436-440

$\mathrm{H}$ Ketamo, mLearning for kindergarten's mathematics teaching, in Wireless and Mobile Technologies in Education Proceedings. IEEE International Workshop, 2002, pp. 167-168

MA Khenissi, F Essalmi, M Jemni, Learner Modeling Using Educational Games: A Review of the Literature. Smart Learn. Environ. 2(1), 1-16 (2015)

WR King, J He, A meta-analysis of the technology acceptance model. Inf. Manag. 43, 740-755 (2006)

Kinshuk, HW Huang, D Sampson, NS Chen, Trends in educational technology through the lens of the highly cited articles published in the Journal of Educational Technology and Society. Educ. Technol. Soc. 16(2), 3-20 (2013)

R Koster, Theory of fun for game design. Paraglyph, (2004)

P Lavín-Mera, P Moreno-Ger, B Fernández-Manjón, Development of educational videogames in m-Learning contexts, in Digital Games and Intelligent Toys Based Education, 2008, pp. 44-51

P Lavin-Mera, J Torrente, P Moreno-Ger, J Vallejo-Pinto, B Fernández-Manjón, Mobile game development for multiple devices in education. Int. J. Emerg. Technol. in Learn., 4(2), 19-26 (2009)

N Litayem, B Dhupia, S Rubab, Review Of Cross-Platforms for Mobile Learning Application Development. (IJACSA) Int. J. Adv. Comput. Sci. Appl., 6(1), 31-39 (2015)

TW Malone, MR Lepper, Making learning fun: A taxonomy of intrinsic motivations for learning Aptitude, learning, and instruction, 1987, pp. 223-253

KL McClarty, A Orr, PM Frey, RP Dolan, V Vassileva, A McVay, A literature review of gaming in education. Gaming in education, 2012

G Moneta, M Csikszentmihalyi, The effect of perceived challenges and skills on the quality of subjective experience. J. Pers. 64(2), 275-310 (1996)

S Myers, Students' Perceptions of Classroom Group Work as a Function of Group Member Selection. Commun. Teach. 26(1), 50-64 (2012)

BC Nelson, B Erlandson, A Denham, Global channels of evidence for learning and assessment in complex game environments. Br. J. Educ. Technol. 42(1), 88-100 (2011)

J Nouch, Mobile Games Market Grew 33 Percent in 2012 to $\$ 9$ Billion. Retrieved December 20, 2015, from http://www. pocketgamer.biz/news/48541/mobile-games-market-grew-33-percent-in-2012-to-9-billion/ (2013)

C O'Malley, G Vavoula, J Glew, J Taylor, M Sharples, P Lefrere, Retrieved December 20, 2015, from. https://hal.archivesouvertes.fr/hal-00696244/document (2005)

D Oblinger, The next generation of educational engagement. J. Interactive Media Educ. 8, 1-18 (2004)

D Oblinger, Space as a change agent. In, D. Oblinger (Ed.), Learning Spaces. EDUCAUSE, Boulder, Colorado, (2006)

D Oblinger, JL Oblinger, JK Lippincott, Educating the net generation (EDUCAUSE, Boulder, Colo, 2005)

F Paraskeva, S Mysirlaki, A Papagianni, Multiplayer online games as educational tools: facing new challenges in learning. Comput. Educ. 54(2), 498-505 (2010)

N Park, KM Lee, PH Cheong, University instructors' acceptance of electronic courseware: An application of the technology acceptance model. J. Comput.-Mediat. Commun. 13(1), 163-186 (2007)

N Peever, D Johnson, J Gardner, Personality \& video game genre preferences, in Proceedings of The 8th Australasian Conference on Interactive Entertainment: Playing the System, 2012

JL Plass, BD Homer, CK Kinzer, J Frye, K Perlin, Learning mechanics and assessment mechanics for games for learning. G4LI White Paper, 2011

L Porter, S Garcia, HW Tseng, D Zingaro, Evaluating student understanding of core concepts in computer architecture ITiCSE'13, 1-3, (2013)

M Prensky, Fun, play and games: What makes games engaging. Digital game-based learning, 2001, pp. 1-05

M Prensky, Digital game-based learning. Comput. Entertain. (CIE), 1(1), 21-21, (2003)

M Prensky, Computer games and learning: Digital game-based learning. Handb. Comput. Game Stud. 18(2005), 97-122 (2005)

K Reid, Disaffection from school (Methuen, London, 1986)

R Saadé, F Nebebe, W Tan, Viability of the technology acceptance model in multimedia learning environments: a comparative study. Interdisciplinary J. E-Learn. Learn. Objects 3(1), 175-184 (2007) 
I Sahin, M Shelley, Considering students' perceptions: The distance education student satisfaction model. Educ. Technol. Soc. 11(3), 216-223 (2008)

J Sandberg, M Maris, K De Geus, Mobile English learning: An evidence-based study with fifth graders. Comput. Educ. 57(1), 1334-1347 (2011)

C Shuler, N Winters, M West, The Future of Mobile Learning: Implications for Policy Makers and Planners, published by United Nations Educational, Scientific and Cultural Organization (UNISCO), (2013)

KA Siek, Y Rogers, KH Connelly, Fat finger worries: how older and younger users physically interact with PDAs, in Human-Computer Interaction-INTERACT, 2005, pp. 267-280

Teamhively, Retrieved December 20, 2015, from http://teamhively.com/638-the-problem-with-5-star-rating-methods (2011)

M Virvou, G Katsionis, On the usability and likeability of virtual reality games for education: The case of VR-ENGAGE. Comput. Educ. 50(1), 154-178 (2008)

A Tlili, F Essalmi, M Jemni, A mobile educational game for teaching computer architecture, in International Conference on Advanced Learning Technologies (ICALT 2015) (2015) pp. 161-163.

A Tlili, F Essalmi, M Jemni, Metric-based approach for selecting the game genre to model personality. in State-of-the-Art and Future Directions of Smart Learning (Springer, Singapore, 2016), pp. 275-279.

A Waraich, Using narrative as a motivating device to teach binary arithmetic and logic gates. In ACM SIGCSE Bulletin, Vol. 36(3), 97-101, (2004)

LE Wickersham, P McGee, Perceptions of satisfaction and deeper learning in an online course. Quarterly Review Distance Educ. 9(1), 73-83 (2008)

MJP Wolf, The Medium of the Video Game (University of Texas Press, Texas, 2004)

$\mathrm{CH}$ Yu, An introduction to computing and interpreting Cronbach Coefficient Alpha in SAS, in Proceedings of 26th SAS User Group International Conference, 2001, pp. 22-25

\section{Submit your manuscript to a SpringerOpen ${ }^{\circ}$ journal and benefit from:}

- Convenient online submission

- Rigorous peer review

- Immediate publication on acceptance

- Open access: articles freely available online

- High visibility within the field

Retaining the copyright to your article

Submit your next manuscript at $\gg$ springeropen.com 